\title{
Celebrating 180 years of financial services
}

Birmingham-based specialist financial services mutual Wesleyan celebrated its 180th anniversary in April. To mark the occasion, Wesleyan is sponsoring Gratitude, an art installation led by global public art producer Wild in Art.

Gratitude will launch in Birmingham in August 2021 and will see 49 uniquely painted sculptures placed around the city in tribute of the NHS and other key workers who have served throughout the pandemic.

Following a UK tour, the sculptures will be auctioned off, with the proceeds donated to NHS Charities Together, who support a variety of NHS services, including hospitals and mental healthcare providers.

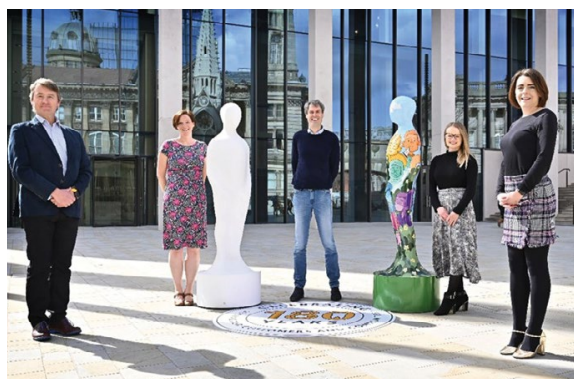

As a specialist in financial solutions for hospital doctors, GPs, dentists and teachers, the partnership with 'Gratitude' is an opportunity for Wesleyan to say thank you to its loyal customers, who have worked tirelessly on the frontline over the past year.

\section{Gingiva and enamel shades for greater individuality}

Whether distinct mucolabial folds, poorly vascularised areas or missing papillae, red aesthetics are becoming more and more important in restorative dentistry. To make gingiva reproduction with composites even more lifelike and individual, SHOFU has added highquality Gingiva shades to the proven Beautifil II System - for a harmonious interplay between red and white aesthetics.

Five Gingiva shades, which can be blended and layered with each other, allow the reproduction of true-to-nature soft tissue areas with great depth and invisible transitions to the tooth. They are indicated primarily in cases of gingival recession, exposed abutments and crown margins, root erosion and missing papillae, and perfectly suited for Class
$\mathrm{V}$ and other restorations. These pasty, non-sticky composites feature superior handling and sculpting properties and can easily and efficiently be polished to a high gloss.

The Enamel shades can also be blended and layered with each other, for unlimited possibilities in aesthetic anterior restorations. The four shades - Translucent, High-Value Translucent, Low-Value Translucent and Amber allow you to easily and efficiently create polychromatic restorations and invisibly repair restorations and dentures. Thanks to their excellent spreadability and sculptability, even fine details of the tooth morphology can be reproduced without difficulty.

For further information contact Shofu UK on 01732783580 or sales@shofu.co.uk.

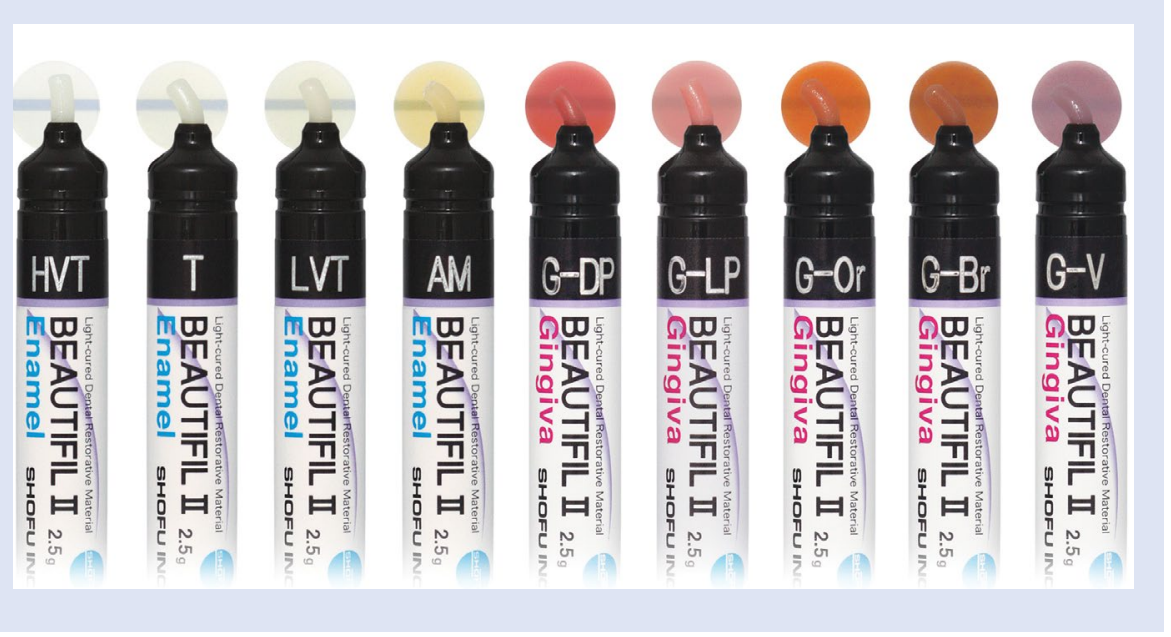

Throughout its history - from its beginnings in 1841 helping factory workers save for sickness and funeral expenses, to its position today as one of the UK's strongest financial institutions and Birmingham's oldest companies - Wesleyan's community has been at its core.

In the turbulence of 2020, Wesleyan launched a 'mutual support package' to help front-line critical workers, as well as providing a welcome boost to schools, charities and community groups in need of equipment and funding amid the COVID-19 crisis. It also launched its 'Wesleyan Wellbeing Hub', which provided 24/7 health and wellbeing support to members and non-members alike.

www.wesleyan.co.uk

\section{Toothbrushing needn't be difficult}

Curaprox has made toothbrushing simpler with the Hydrosonic Easy.

Offering three powerful cleaning modes, this electric toothbrush comes with two teardropshaped brush heads with ultra-soft CUREN filaments.

The ergonomic

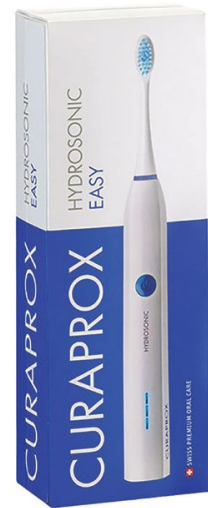

design of these

brush heads not

only ensures each tooth is effectively enveloped, but that all areas of the oral cavity can also be accessed easily.

Once activated, the Hydrosonic Easy produces a hydrodynamic cleaning effect, whereby the movements produced by the device set the water, saliva and toothpaste in motion. This enables the fluids to remove plaque, food particles and other debris from interdental spaces and other notoriously hard-to-reach areas.

Help patients simplify oral care by recommending the Hydrosonic Easy today.

For more information call 01480 862084, email info@curaprox.co.uk or visit www.curaprox.co.uk. 